\title{
Bitrokanterik Çap Mesafesi Genç Yetişkin Erkeklerin Flamingo Denge Testi Sonuçlarını Etkiler Mi?
}

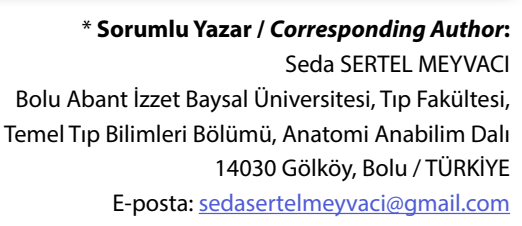

Alındı/Received: 19 Nisan / April 2020 Düzeltildi/Revised: 24 Haziran / June 2020 Kabul/Accepted: 25 Haziran / June 2020 Yayımlandı/Published: 29 Haziran / June 2020
1 Dr. Öğr. Üyesi | Bolu Abant İzzet Baysal Üniversitesi, Tıp Fakültesi, Anatomi Anabilim Dalı, Bolu / TÜRKiYE ${ }^{2}$ Prof. Dr. | İstanbul Medeniyet Üniversitesi, Tıp Fakültesi, Biyoistatistik ve Tıp Bilişimi Anabilim Dalı, İstanbul / TÜRKiYE

\section{Does Bitrochanteric Diameter Distance Affect the Flamingo} Balance Test Results of Young Adult Men?

Bu çalışmada, sağlıklı genç erkeklerde bitrokanterik çap ve Flamingo denge testi performans düzeyi arasındaki ilişkiyi incelemek amaçlandı. Araştırmaya 18-25 yaş aralığında 96 sağlıklı genç erkek alınmıştır. Olguların beden kitle indeksi normal aralıkta 20-24,99 kg/m² olmak üzere sınırlandırılmıştır. Olguların denge performansı Flamingo Denge Testi ile değerlendirilmiştir. Bitrokanterik çap ölçümü başta olmak üzere ayak parametreleri dijital kaliper kullanarak değerlendirilmiştir. Flamingo denge testi ile bitrokanterik çap arasındaki basit ve kısmi korelasyonlar Pearson korelasyon analizi ile değerlendirildi. Bu çalışmadan elde ettiğimiz sonuçlar sağlıklı genç erkeklerde bitrokanterik çap ve Flamingo denge testi performans düzeyi arasında, ayak parametreleri ve Beden Kitle Indeksi değerleri kontrol altına alınarak ve alınmayarak istatistiksel olarak incelendi. Flamingo denge testi ile bitrokanterik çap arasındaki ilişki her iki değerlendirmede de istatistiksel olarak anlamlı bir ilişki olmadığını göstermiştir ( $p>0,05)$. Çalışmamızın sağlıklı erkek genç yetişkinlerde trokanterik çap parametresi ve Flamingo denge performansı biyomekaniği arasındaki ilişkinin anlamlı bulunmaması ile bu sonuçların ışı̆̆ında ileride yapılacak klinik araştırmaların planlanmasında katkı sağlayarak yararlı olabileceği kanısındayız.

Anahtar Sözcükler: Bitrokanterik çap, Flamingo denge testi, ayak parametreleri, sağlıklı genç erkeklerl, normalizasyon

\section{Giriş}

Kalça stabilizasyonunda primer öneme sahip olan m. gluteus medius, en çok kalça eklemin abdüksiyon ve iç rotasyon hareketleri yapılırken aktiftir (Earl, 2005; Hamstra-Wright ve Bliven, 2012). Kalçanın stabilizasyonunun biyomekaniği, yürümenin basma fazının, tek ayak üzerinde durulan topuk kalkış bölümünde muskuloskeletal kaldıraç sistemi gibi fonksiyona sahiptir (Şeker vd., 2014). Bu hareketin biyomekaniğini düşündüğümüzde $m$. gluteus medius, internal kuvvettir (Neumann, 2010).

M. gluteus medius'un insertio bölgesi femur'da trochanter major'dür (Ren vd., 2019). Vücutta sağ ve sol femur'un trochanter major'leri arası mesafe olan bitrokanterik çap,

\section{Abstract}

In this study, the purpose was to examine the relation between trochanteric diameter and Flamingo Balance Test performance levels in healthy young men. A total of 96 bealthy young men between the ages of 18 and 25 were included in the study. The Body Mass Index of the cases was limited as $20-24.99 \mathrm{~kg} / \mathrm{m}^{2}$ within normal range. The balance performance of the subjects was evaluated with Flamingo Balance Test. Foot parameters, especially trochanteric diameter measurements, were evaluated by using a digital caliper. Simple and partial correlations between Flamingo Balance Test and trochanteric diameter were evaluated with Pearson Correlation Analysis. The results of this study were examined statistically between trochanteric diameter and performance of Flamingo Balance Test in healthy young men, by controlling and not controlling the values of the feet parameters and Body Mass Index values. The relation between Flamingo Balance Test and trochanteric diameter was not statistically significant in both evaluations ( $p>0.05$ ). We believe that our study might be useful in planning future clinical studies in the light of these results, as it was determined that there was no significant relationship between the trochanteric diameter parameter and Flamingo Balance Performance biomechanics in bealthy male young adults.

Key Words: Bitrochanteric diameter, Flamingo balance test, foot parameters, bealthy young men, normalization

stabilizasyon hareketinde kaldıraç kolu uzunluğu olarak eklem kinezyolojisinin bir parçasıdır.

İnsan vücudunda ölçüm alma tekniği olarak antropometri, insan vücudunun şeklini kantitatif olarak ifade etme tekniği diye tanımlanabilir (Kanchan ve Krishan, 2011). Insan vücudunda antropometrik değerlendirmeler, çevre, uzunluk, çap ve yağ dokusu ölçümlerini içermektedir. Literatürdeki çalışmalar incelediğinde, antropometrik ölçüm yöntemlerini kullanan birçok araştırma olduğu ancak bitrokanterik çap üzerine yapılmış çalışmaların sınırlı olduğu görüldü (Lim vd., 2004; Wall-Scheffler, 2012; Noble vd., 2019).

Bu çalışmanın amac1, 18-25 yaş arası genç yetişkin erkeklerde bitrokanterik çap mesafesini ölçmek ve bu 
mesafenin kalça stabilizasyonu ön planda olan Flamingo denge testi gibi tek ayak üzerinde durulan bir test üzerine etkisi olup olmadığını değerlendirmektir. Bu çalışmadan elde edilecek sonuçların araştırmalarda ve klinikte yol gösterici olacağı düşünülmektedir.

\section{Gereç ve Yöntem}

Araştırmamızda, yaş aralığ1 18-25 arasında olan 96 erkek olgu değerlendirildi. Denge testi sonuçlarını, beden kitle indeksi (BKI)'nin etkilediği bilinmektedir ve araştırmalarda belirtilmiştir (Greve vd., 2007). BKİ, bireyin vücut ağırllğııın (kg), boy uzunluğunun (m cinsinden) karesine $\left(\mathrm{BK} \dot{\mathrm{I}}=\mathrm{kg} / \mathrm{m}^{2}\right)$ bölünmesiyle elde edilen bir değerdir. Bu nedenle biz de araştırmamızdaki sonuçlarımızın, BKİ değerinden etkilenmemesi için normal sınır aralığında olan olguları araştırmaya dahil ettik. Dünya Sağlık Örgütü (DSÖ) tarafından kabul edilen BKI üzerine bir uluslararası sinıflandırma geliştirmiştir. Bu sınıflandırmaya göre BKİ 18,50-24,99 $\mathrm{kg} / \mathrm{m}^{2}$ arası normal aralık olarak tanımlanmıştır (DSÖ, 2004). Araştırmada incelediğimiz olguların BKİ 20,00$24,99 \mathrm{~kg} / \mathrm{m}^{2}$ arasında olduğu görülmüştür.

Menstrüel siklusun fazlarının kas iskelet sistemini ve bunun sonucu olarak postüral stabiliteyi etkilediği araştırmada belirtilmiştir (Fridén vd., 2003). Bunun sonucu olarak çalışmamızda, her kadının hormonsal döngüsünün farklı olması, standardize edilmesinin güç olması ve bu durumun kas-iskelet sisteminde değişikliklere sebep olarak sonuçlarımızı etkiyeceği düşüncesiyle daha güvenilir sonuçlar elde etmek için sadece erkek olgular üzerinde çalışılmıştır.

Olguların yaş, kilo, boy ve BKİ gibi demografik özellikleri de kayıt edilmiştir. Çalışmaya dâhil edilen kişilere araştırma ile ilgili bilgi verilerek yazılı onayları alınmıştır. Çalışma protokolü, Bolu Abant İzzet Baysal Üniversitesi Klinik Araştırmalar Etik Kurulu tarafından onaylanmış (Protokol No: 2020/61) ve veriler retrospektif olarak 2018.08.01.1380 numaralı proje ile Bolu Abant İzzet Baysal Üniversitesi Bilimsel Araştırma Projesi (BAP) tarafından desteklenmiş çalışmadan sağlanmıstır.

Her olgu için bitrokanterik çap mesafesi, ayak parametreleri ve flamingo denge testi değerlendirildi.

\section{Flamingo denge testi (FDT)}

Statik denge testidir. Testin geçerlilik ve güvenilirliği rapor edilmiştir. Test bireyin dominant ekstremitesi üzerine uygulanır ancak uygulama öncesi bireylere testin içeriği ve nasıl uygulanacağı anlatılır. Bireyler literatürde belirtilen ölçülerde hazırlanan, $15 \mathrm{~cm}$ uzunluğundaki, 4 $\mathrm{cm}$ genişliğindeki tahta plaka üzerinde dengede durmaya çalışırken, 1 dakika içinde kaç defa düştüğü kaydedilir. $\mathrm{Bu}$ süre içinde her düşme esnasinda kronometre durdurularak tekrardan bireyin pozisyon alması beklenir.
$\mathrm{Bu}$ araştırmada, sağ ve sol kalça stabilizasyonunu incelemek için testi her iki alt ekstremite içinde uyguladik. Test uygulanırken her düşme esnasında hata sayısının kaydedilmesine ek olarak ilk düşme esnasındaki hata zamanını da değerlendirdik (Tsigilis vd., 2002; Haksever vd., 2017).

\section{Bitrokanterik çap mesafesi}

Bireyler ayakta duruş pozisyonundayken sağ ve sol femura ait trochanter major'ler aras1 mesafe 0,01 mm'lik bir okuma hassasiyeti olan 0-1000 mm'lik tek çene dijital kumpas ile ölçüm yapildı.

\section{Ayak parametreleri}

Ayak uzunluğu, ayak genişliği, topuk genişliği, ayak yüksekliği, medial malleol yüksekliği (mmy), lateral malleol yüksekliği (lmy), I. metatarsal eklemin (mtp I) yüksekliği, V. metatarsal eklemin yüksekliği (mtp V), ayak apeks yüksekliği ve navikülar yüksekliği de olmak üzere 10 tane ayak paremetresi değerlendirilmiştir. Sağ ve sol ayağa ait ölçümler $0,1 \mathrm{~mm}$ 'lik bir okuma hassasiyeti olan 0-300 mm'lik Digital kumpas ile yapıldı ve veriler Excel dosyasına kayıt edildi (Özaslan vd., 2003; Xu vd., 2018; Zeybek vd., 2008).

\section{Dâhil olma kriterleri}

- Denge bozukluğuna sebep olacak nörolojik veya ortopedik bir hastalığı olmaması

- Ayak deformitesinin olmamasi

- Normal postüre ve asemptomatik duruma sahip olmas 1

- Ayak ve kas iskelet sistemini etkileyecek herhangi bir operasyon geçirmiş olmamas1

- M. gluteus medius kas kuvvetinin (5) normal olmas1

- Dominant ayağı sağ taraf olması

- BKİ normal sinirlarda (18,50-24,99 kg/m²) olmas1

- Yaş1 18-25 aralığında olması

- Cinsiyetin erkek olmasi

- Spor geçmişinin olmamas1

- Gönüllü olmas1

\section{Hariç olma kriterleri}

- Denge bozukluğuna sebep olacak nörolojik veya ortopedik bir hastalı̆̆ olmas1

- Ayak deformitesinin olmas1

- Normal postüre ve asemptomatik duruma sahip olmamasi

- Ayak ve kas iskelet sistemini etkileyecek herhangi bir operasyon geçirmiş olması

- M. glutens medius kas kuvvetinin (5) normal olmamas1

- Dominant ayağı sağ taraf olmamas1 
Sertel Meyvacı ve Ankaralı|Antropoloji (39) (2020)

Tablo 1. Genç yetişkin erkek olguların demografik ve antropometrik özellikleri

\begin{tabular}{|c|c|c|c|c|c|}
\hline Birey No & $\mathbf{N}$ & En az & En çok & Ortalama & $\begin{array}{c}\text { Standart } \\
\text { Sapma }\end{array}$ \\
\hline Yaş (y1l) & 96 & 18 & 25 & 20,36 & 2,02 \\
\hline Boy $(\mathrm{cm})$ & 96 & 158,00 & 191,20 & 176,22 & 6,32 \\
\hline Kilo $(\mathrm{kg})$ & 96 & 54,80 & 89,45 & 71,53 & 7,65 \\
\hline BKİ $\left(\mathrm{kg} / \mathrm{m}^{2}\right)$ & 96 & 20,00 & 24,99 & 23,00 & 1,73 \\
\hline Sağ ayak uzunluğu (cm) & 96 & 21,85 & 29,49 & 26,27 & 1,31 \\
\hline Sağ ayak genişliği $(\mathrm{cm})$ & 96 & 6,69 & 105,00 & 11,51 & 9,77 \\
\hline Sağ topuk genişliği (cm) & 96 & 4,95 & 7,32 & 6,27 & 0,50 \\
\hline Sağ ayak mmy $(\mathrm{cm})$ & 96 & 7,20 & 10,00 & 8,44 & 0,61 \\
\hline Sağ ayak lmy (cm) & 96 & 3,40 & 8,20 & 7,09 & 0,62 \\
\hline Sağ bimalleolar çap (cm) & 96 & 3,00 & 13,00 & 7,43 & 1,10 \\
\hline Sağ mtp I yükseklik (cm) & 96 & 2,60 & 6,30 & 3,34 & 0,43 \\
\hline Sağ mtp V yükseklik (cm) & 96 & 1,60 & 7,50 & 2,23 & 0,57 \\
\hline Sağ dorsal ark yükseklik (cm) & 96 & 5,70 & 8,50 & 7,17 & 0,49 \\
\hline Sağ naviküler yükseklik (cm) & 96 & 3,20 & 6,50 & 4,84 & 0,67 \\
\hline Sol ayak uzunluğu (cm) & 96 & 23,30 & 29,61 & 26,39 & 1,23 \\
\hline Sol ayak genişliği (cm) & 96 & 9,13 & 11,57 & 10,53 & 0,56 \\
\hline Sol topuk genişliği $(\mathrm{cm})$ & 96 & 5,02 & 7,80 & 6,35 & 0,52 \\
\hline Sol ayak mmy $(\mathrm{cm})$ & 96 & 7,10 & 10,00 & 8,44 & 0,60 \\
\hline Sol ayak $\operatorname{lmy}(\mathrm{cm})$ & 96 & 6,00 & 8,50 & 7,14 & 0,53 \\
\hline Sol bimalleolar çap $(\mathrm{cm})$ & 96 & 6,11 & 74,40 & 8,29 & 6,90 \\
\hline Sol mtp I yükseklik (cm) & 96 & 2,40 & 13,50 & 3,34 & 1,10 \\
\hline Sol mtp V yükseklik (cm) & 96 & 1,60 & 7,50 & 2,23 & 0,59 \\
\hline Sol dorsal ark yükseklik (cm) & 96 & 5,70 & 8,40 & 7,09 & 0,51 \\
\hline Sol naviküler yükseklik (cm) & 96 & 3,00 & 6,50 & 4,74 & 0,67 \\
\hline Bitrokanterik çap $(\mathrm{cm})$ & 96 & 25,94 & 37,55 & 33,23 & 1,86 \\
\hline
\end{tabular}

- BKİ normal sinirlarda $\left(18,50-24,99 \mathrm{~kg} / \mathrm{m}^{2}\right)$ olmamas1

- Yaş1 18-25 aralığında olmamas1

- Cinsiyetin kadin olmasi

- Spor geçmişinin olmasi

- Gönüllü olmaması

\section{Istatistik analiz}

Elde edilen verilere ait tanımlayıc istatistikler ortalama ve standart sapma olarak hesaplandi. Flamingo denge testiile bitrokanterik çap arasındaki basit ve kısmi korelasyonlar Pearson korelasyon analizi ile değerlendirildi. İstatistik anlamlılık düzeyi olarak $\mathrm{p}<0,05$ kabul edildi.

\section{Bulgular}

Araştırmamızda Flamingo denge testi ile bitrokanterik çap arasındaki ilişki istatistiksel olarak 2 farklı yöntem ile incelenmiştir. Illk incelemede vücuttaki antropometrik parametrelerden, denge ile ilişkisi diğer parametrelere göre ön planda olan ayak parametreleri, boy ile kilo parametrelerinden hesaplanan BKI'si dikkate alınmıştır ve bu parametrelerin tanımlayıcı değerleri Tablo 1'de verilmiştir. Genç yetişkin erkek olguların Flamingo denge testi sonuçları ve tanımlayıc istatistik değerleri ise Tablo 2'de verilmiştir.

Yapılan analizde, 10 tane ayak parametresi ve 
Sertel Meyvac1 ve Ankaralı|Antropoloji (39) (2020)

Tablo 2. Genç yetişkin erkek olguların Flamingo denge testi sonuçlarının tanımlayıcı değerleri

\begin{tabular}{cccccc}
\hline Flamingo Denge Testi & N & En az & En çok & Ortalama & $\begin{array}{c}\text { Standart } \\
\text { Sapma }\end{array}$ \\
\hline Sağ hata sayısı & 96 & 0 & 23,00 & 8,01 & 5,67 \\
Sol hata sayısı & 96 & 0 & 24,00 & 7,89 & 5,67 \\
Sağ ilk hata zamanı & 96 & 1,48 & 60,00 & 12,67 & 15,32 \\
Sol ilk hata zamanı & 96 & 1,33 & 60,00 & 13,56 & 15,67 \\
\hline
\end{tabular}

BKİ değerleri istatistik olarak kontrol altına alınarak, Flamingo denge testi ile bitrokanterik çap arasındaki ilişki incelenmiştir. Sonuçlar incelendiğinde Flamingo denge testi sonuçları olan sağ hata sayısı, sol hata sayısı, sağ ilk hata zamanı ve sol ilk hata zamanı ile bitrokanterik çap arasındaki ilişki istatistik olarak anlamlı bulunmadı (Tablo 3).

Yapılan diğer analizde, 10 tane ayak parametresi ve BKİ değerleri istatistiksel olarak kontrol altına alınmayarak Flamingo denge testi ile bitrokanterik

Tablo 3. Ayak parametreleri ve BKİ değerleri kontrol altına alınarak Flamingo denge testi ile bitrokanterik çap arasındaki kısmî korelasyonlar

\begin{tabular}{cccc}
\hline & \multicolumn{3}{c}{ Bitrokanterik Çap } \\
\cline { 2 - 4 } Flamingo Denge Testi & $\mathbf{N}$ & $\mathbf{r}$ & $\mathbf{p}$ \\
\hline Sağ hata sayısı & 96 & $-0,097$ & 0,410 \\
Sol hata sayıs1 & 96 & $-0,143$ & 0,221 \\
Sağ ilk hata zamanı & 96 & 0,078 & 0,506 \\
Sol ilk hata zamanı & 96 & 0,065 & 0,581 \\
\hline
\end{tabular}

Tablo 4. Flamingo denge testi ile bitrokanterik çap arasındaki basit korelasyonlar

\begin{tabular}{cccc}
\hline \multirow{2}{*}{ Flamingo Denge Testi } & \multicolumn{3}{c}{ Bitrokanterik Çap } \\
\cline { 2 - 4 } & $\mathbf{N}$ & $\mathbf{r}$ & $\mathbf{p}$ \\
\hline Sağ hata sayısı & 96 & $-0,097$ & 0,410 \\
Sol hata sayısı & 96 & $-0,143$ & 0,221 \\
Sağ ilk hata zamanı & 96 & 0,078 & 0,506 \\
Sol ilk hata zamanı & 96 & 0,065 & 0,581 \\
\hline
\end{tabular}

çap arasındaki ilişki değerlendirilmiştir. Sonuçlar incelendiğinde, Flamingo denge testi sonuçları olan sağ hata sayıs1, sol hata sayısı, sağ ilk hata zamanı ve sol ilk hata zamanı ile bitrokanterik çap arasındaki ilişki istatistik olarak anlamlı olmadığ1 tespit edildi (Tablo 4).

\section{Tartışma}

Antropometri, insan vücudunun büyüklügünnü, oranlarını ve kompozisyonunu değerlendirmek için taşınabilir, evrensel olarak uygulanabilir, en ucuz ve invaziv olmayan tek teknik olarak kabul edilmektedir (Sen ve Ghosh, 2008). Kalça stabilizasyonunu etkileyecek bütün faktörlerin bilinmesi, yapılacak çalışmaların doğru planlanmasında, bireysel antropometrik farklılıkları dikkate alarak araştırmalarda doğru sonuçların elde edilmesinde önemlidir ve daha fazla bilgi gerektirmektedir. Bu antropometrik ölçüm değerleri, yaş, boy, kilo, cinsiyet ve etnik orjin başta olmak üzere birçok faktörden etkilenmektedir. Bu nedenle antropometrik ölçümleri etkileyen faktörler dikkate alınarak planlanmış birçok araştırma yapılımışıı (Kaptoge vd., 2003; İşeri ve Arslan, 2009; Sertel Meyvaci vd., 2020)

Bizim çalışmamızda yaş, BKİ ve cinsiyet sınırlandırılarak bitrokanterik çap değerinin denge testi sonuçları üzerine etkisini inceledik.

Antropometrik parametrelerin denge üzerine etkisini inceleyen araştırmalarda, boy, gövde-sefalik uzunluk, üst ekstremite uzunluğu, alt ekstremite uzunluğu, ayak genişliği, topuk genişliği, ayak uzunluğu, kalça-zemin mesafesi ve diz-zemin mesafesinin denge parametreleri üzerine etkisi olduğunu rapor etmişlerdir (Keionen vd., 2003; Greve vd., 2007).

Biz de araştırmamızda, bitrokanterik çap ölçümünün Flamingo denge testi sonuçları üzerine etkisini erkek olgularda BKI ile ayak parametrelerine düzeltme yapılarak ve yapılmayarak araştırdık. Elde edilen bulgular değerlendirildiğinde, bitrokanterik çap ile Flamingo denge testi sonuçları üzerine etkisi olmadığ 1 tespit edildi.

Bitrokanterik çap üzerine yapılmış araştırmaları incelediğimizde, bazı vücut antropometrik ölçümleri ile yürüme hızı arasındaki ilişkinin çalışıldığı bir araştırmada yaş aralığ1 19-35 arasında olan erkek ve kadın olgular değerlendirilmiştir. Çalışmalarında bitrokanterik çap değeri arttıkça, yürüme hızının da arttı̆̆ını belirtmişlerdir (Wall-Scheffler, 2012). Yürüme hızı ile pelvis biyomekaniği arasındaki ilişkinin incelendiği bir araştırmada ise, kadın olgularda bitrokanterik çap, BKI 
ve alt ekstremite uzunluğu ile yürüme hızı arasında pozitif ilişki olduğu bulunmuştur (Wall-Scheffler ve Myers, 2017). Diğer bir araştırmada ise yürüme sırasında kalça addüksiyonu ile bitrokanterik çapın, bacak uzunluğuna oranı arasında orta derecede korelasyon olduğu tespit edilmiştir (Chumanov vd., 2008).

Bizim çalışmamızda ise bitrokanterik çap ile Flamingo denge testi arasındaki ilişki incelenmiştir ve aralarında ilişki olmadığı tespit edilmiştir. Fakat literatür taramamızda bitrokanterik çap değerinin, denge testi üzerine etkisini inceleyen araştırma bulamamıs olmamız bu konuda çalışmaların yetersiz olduğunu ve yeni çalışmalara ihtiyaç olduğunu göstermektedir.

\section{Sonuç}

Denge, destek merkezi üzerinde vücudun ağırlık merkezini koruyabilme yeteneği olarak ifade edilebilir (Emery vd., 2005). Flamingo denge testindeki gibi, tek ayak üzerinde durularak gösterilen performansın, muskuloskeletal kaldıraç sistemi komponentlerini düşündügümüzde $m$. gluteus medius ve bitrokanterik çap ön plana çıkmaktadır.

$\mathrm{Bu}$ çalışmada, cinsiyeti erkek, BKİ değeri normal sınırlarda olan ve 18-25 yaş aralığındaki kişiler değerlendirildi. Denge performasında, yerle temasindan dolay1 proprioseptif duyu girdisinin olduğu ayak bölgesinin parametreleri ve BKI'si değeri yapılan istatistiksel testlerde kontrol altına alınarak ve alınmayarak Flamingo denge testi ile bitrokanterik çap arasındaki ilişki, her iki değerlendirme sonucunda da istatistik olarak anlamlı bulunmadı.

Çalışma sonucunda, yaş aralı̆̆ı 18-25 ve BKI değerleri normal olan erkekler için, ayak parametreleri ve bitrokanterik çap dikkate alınarak Flamingo denge testine ait normatif veriler elde edilmiş ve bu bilgiler literatüre kazandırılmıştır.

Sonuç olarak, normal postüre sahip sağllklı genç yetişkinlere ait antropometrik ölçümlerinden bitrokanterik çap parametresi ve fonksiyonel denge performansı biyomekaniği arasındaki ilişkinin anlamlı bulunmaması ile bu sonuçların 1şı̆̆ında ileride yapılacak klinik araştırmaların planlanmasında ve çeşitli performans çalışmalarının değerlendirilmesinde katkı sağlayarak yararlı olabileceği kanısındayız.

\section{Teşekkür}

Bu çalışmada kullanılan veriler 2018.08.01.1380 numaralı BAP projesi sonucunun bir kısmından elde edilmiştir. Bolu Abant İzzet Baysal Üniversitesi Bilimsel Araştırma Projeleri Koordinatörlüğü’ne teşekkür ederiz.

\section{Kaynakça}

Chumanov, E. S., Wall-Scheffler, C., ve Heiderscheit, B. C. (2008). Gender differences in walking and running on level and inclined surfaces. Clinical Biomechanics, 23(10), 1260-1268. https://doi.org/10.1016/j.clinbiomech.2008.07.011

Earl, J. E. (2005). Gluteus medius activity during 3 variations of isometric single-leg stance. Journal of Sport Rehabilitation, 14(1), 1-11. https://doi.org/10.1123/jsr.14.1.1

Emery, C. A., Cassidy, J. D., Klassen, T. P., Rosychuk, R. J., ve Rowe, B. H. (2005). Development of a clinical static and dynamic standing balance measurement tool appropriate for use in adolescents. Physical Therapy, 85(6), 502-514. https://doi. org $/ 10.1093 / p t j / 85.6 .502$

Fridén, C., Hirschberg, A. L., Saartok, T., Bäckström, T., Leanderson, J., ve Renström, P. (2003). The influence of premenstrual symptoms on postural balance and kinesthesia during the menstrual cycle. Gynecological Endocrinology, 17(6), 433-440. https://doi.org/10.1080/09513590312331290358

Greve, J., Alonso, A., Bordini, A. C. P. G., ve Camanho, G. L. (2007). Correlation between body mass index and postural balance. Clinics, 62(6), 717-720. https://doi.org/10.1590/ $\underline{\mathrm{S} 1807-59322007000600010}$

Haksever, B., Düzgün, İ., Yüce, D., ve Baltacı, G. (2017). Sağlıklı bireylere standart denge eğitiminin dinamik, statik denge ve fonksiyonellik üzerine etkileri. Gą̧i Sağlık Bilimleri Dergisi, 2(3), 40-49.

Hamstra-Wright, K. L., ve Bliven, K. H. (2012). Effective exercises for targeting the Gluteus medius. Journal of Sport Rehabilitation, 21(3), 296-300. https://doi.org/10.1123/jsr.21.3.296

İşeri, A., ve Arslan, N. (2009). Estimated anthropometric measurements of Turkish adults and effects of age and geographical regions. International Journal of Industrial Ergonomics, 39(5), 860-865. https://doi.org/10.1016/i. ergon.2009.02.007

Kanchan, T., ve Krishan, K. (2011). Anthropometry of hand in sex determination of dismembered remains - A review of literature. Journal of Forensic and Legal Medicine, 18(1), 14-17. https://doi.org/10.1016/i.jflm.2010.11.013

Kaptoge, S., Dalzell, N., Loveridge, N., Beck, T. J., Khaw, K. T., ve Reeve, J. (2003). Effects of gender, anthropometric variables, and aging on the evolution of hip strength in men and women aged over 65. Bone, 32(5), 561-570. https://doi.org/10.1016/ $\underline{\mathrm{S} 8756-3282(03) 00055-3}$

Keionen, P., Kauranen, K., ve Vanharanta, H. (2003). The relationship between anthropometric factors and bodybalancing movements in postural balance. Archives of Physical Medicine and Rehabilitation, 84(1), 17-22. https://doi. org/10.1053/apmr.2003.50058

Lim, S., Joung, H., Shin, C. S., Lee, H. K., Kim, K. S., Shin, E. K., Kim, H. Y., Lim, M. K., ve Cho, S. Il. (2004). Body composition changes with age have gender-specific impacts on bone mineral density. Bone, 35(3), 792-798. https://doi. org/10.1016/j.bone.2004.05.016 
Neumann, D. A. (2010). Kinesiology of the hip: A focus on muscular actions. Journal of Orthopaedic and Sports Physical Therapy, 40(2), 82-94. https://doi.org/10.2519/jospt.2010.3025

Noble, J., Flavel, A., Aviv, R., ve Franklin, D. (2019). Forensic anthropological standards for cranial sex estimation in Canada: preliminary results. Australian Journal of Forensic Sciences, 51(sup1), S1-S4. https://doi.org/10.1080/00450618 .2019 .1569720

Özaslan, A., İşcan, M. Y., Özaslan, I., Tuğcu, H., ve Koç, S. (2003). Estimation of stature from body parts. Forensic Science International, 132(1), 40-45. https://doi.org/10.1016/S03790738(02)00425-5

Ren, H., Huang, Q., He, J., Wang, Y., Wu, L., Yu, B., ve Zhang, D. (2019). Does isolated greater trochanter implication affect hip abducent strength and functions in intertrochanteric fracture? BMC Musculoskeletal Disorders, 20(1), 1-7. https:// doi.org/10.1186/s12891-019-2457-8

Şeker, A., Talmaç, M. A., ve Sarıkaya, İ. (2014). Yürüme biyomekaniği. TOTBID Dergisi, 13(4), 314-324. https://doi. org/10.14292/totbid.dergisi.2014.35

Sen, J., ve Ghosh, S. (2008). Estimation of stature from foot length and foot breadth among the Rajbanshi: An indigenous population of North Bengal. Forensic Science International, 181(1-3), 55.e1-55.e6. https://doi.org/10.1016/j. forsciint.2008.08.009

Sertel Meyvaci, S., Meyvaci, T., Kosif, R., Diramali, M., ve Ankarali, H. (2020). Effect of foot anthropometric measurements on postural stability. Experimental Biomedical Research, 3(3), 176190. https://doi.org/10.30714/j-ebr.2020361056

Tsigilis, N., Douda, H., ve Tokmakidis, S. P. (2002). Test-retest reliability of the eurofit test battery administered to university students. Perceptual and Motor Skills, 95(3_suppl), 1295-1300. https://doi.org/10.2466/pms.95.8.1295-1300

Wall-Scheffler, C. M. (2012). Size and shape: Morphology's impact on human speed and mobility. Journal of Anthropology, 2012, 1-9. https://doi.org/10.1155/2012/340493

Wall-Scheffler, C. M., ve Myers, M. J. (2017). The biomechanical and energetic advantages of a mediolaterally wide pelvis in women. Anatomical Record, 300(4), 764-775. https://doi. org/10.1002/ar.23553

Xu, M., Hong, Y., Li, J. X., ve Wang, L. (2018). Foot morphology in Chinese school children varies by sex and age. Medical Science Monitor, 24, 4536-4546. https://doi.org/10.12659/ MSM.906030

Zeybek, G., Ergur, I., ve Demiroglu, Z. (2008). Stature and gender estimation using foot measurements. Forensic Science International, 181(1-3), 54.e1-54.e5. https://doi.org/10.1016/j. forsciint.2008.08.003

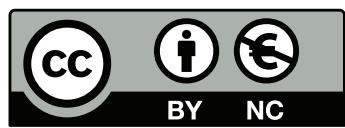

2020. Telif haklar1 yazar(lar)a aittir.

Bu makale Creative Commons Atıf-GayriTicari 4.0 Uluslararası (CC BY-NC 4.0) lisansının hüküm ve şartları altında yayımlanan açık erişimli bir makaledir. 